\title{
Current Diagnosis and Management of Syringocele: A Review
}

\author{
Jonathan Melquist, Vidit Sharma, Daniella Sciullo, Heather McCaffrey, S. Ali Khan \\ Department of Urology, SUNY at Stony Brook Medical Center, Stony Brook, New York, USA
}

\begin{abstract}
Cowper's syringocele is a rare but an under-diagnosed cystic dilation of the Cowper's ducts and is increasingly being recognized in the adult population. Recent literature suggests that syringoceles be classified based on the configuration of the duct's orifice to the urethra, either open or closed, as this also allows the clinical presentations of 2 syringoceles to be divided, albeit with some overlap. Usually post-void dribbling, hematuria, or urethral discharge indicate open syringocele, while obstructive symptoms are associated with closed syringoceles. As these symptoms are shared by many serious conditions, a working differential diagnosis is critical. Ultrasonography coupled with retro and ante grade urethrography usually suffices to diagnose syringocele, but supplementary procedures - such as cystourethroscopy, computed tomography scan, and magnetic resonance imaging - can prove useful. Conservative observation is first recommended, but persistent symptoms are usually treated with endoscopic marsupialization unless contraindicated. Upon reviewing the literature, this paper addresses the clinical anatomy, classification, presentation, diagnosis, and treatment of syringoceles in further detail.
\end{abstract}

Key words: Cowper's glands; dilation; urethral obstruction; perineum; urinary incontinence Int Braz J Urol. 2010; 36: 3-9

\section{INTRODUCTION}

Cowper's syringocele is an uncommon but an under-diagnosed cystic dilation of the Cowper's gland ducts. Syringoceles are traditionally viewed as a rare condition afflicting the pediatric population but are increasingly being recognized in the adult population. They are frequently not detailed in major uropathology, radiology, and urologic textbooks even though they can cause severe lower urinary tract symptoms by compressing the urethra or diverting urinary flow. This paper reviews the current literature on the clinical anatomy, classification, clinical presentation, diagnosis and treatment of syringoceles.

\section{FUNCTIONAL ANATOMY OF COWPER'S GLANDS AND DUCTS}

Cowper's glands are composed of two exocrine structures located in the deep perineal pouch between fascial layers of the urogenital diaphragm. They excrete pre-ejaculate into the genito-urinary tract (1). The glands are composed of lobules made of epithelial cells aligned in acinar formation that secrete into the arborized collecting system. The glands eventually form two collecting ducts that measure on average $2.5 \mathrm{~cm}$ each. Although anatomic variations exist, the majority of ducts combine to make one confluent passage that opens at the posterior aspect of the bulbous urethra $(2,3)$. 


\section{CLINICAL MANIFESTATION AND CLASSIFICATION OF SYRINGOCELES}

The true prevalence of Cowper's syringocele is unknown. It is thought to be more pronounced in the pediatric population perhaps because symptoms are appreciated preferentially at a younger age. However, there is a growing body of literature suggesting the problem exists notably in the adult population as well. There are at least 10 case reports describing this rare anomaly in patients over the age of 18 (4).

Traditionally, Cowper's syringocele has been divided into four types: 1) simple syringocele with a modestly dilated duct; 2) perforated syringocele with patulous communication with the urethra; 3 ) imperforate syringocele with a dilated bulbous duct; 4) ruptured syringocele that leaves its covering membrane in the urethra often acting in a "ball-on-chain" fashion to cause obstruction (5). Based on building luminal pressures within the ducts, syringoceles may follow a standard maturation from simple to imperforate to either perforated or ruptured, but more data is needed to confirm this hypothesis.

Recent review suggests, however, that syringoceles should be grouped based on the configuration of the duct's orifice to the urethra, as this also allows the clinical presentations of syringoceles to be divided (Table-1). For instance, closed syringoceles have cystically occluded ducts that cause the duct to dilate externally against the urethra and cause obstructive symptoms. Open syringoceles have a continuous lumen between the urethra and the cystic ducts, mimicking a urethral saccule and manifesting as post-void dribbling (6-8). Obstructive symptoms may also manifest in open syringoceles if the remnant membrane is oriented in the urethra to impede flow. Furthermore, grouping syringoceles into these categories accounts for the 4 categories of Maizel's et al., since simple, perforated, and ruptured syringoceles merge into open syringoceles and imperforate syringoceles are classified as closed.

A review of 15 consecutive children with Cowper's syringocele proposed a similar simplified classification. It classified two variants: non-obstructing syringoceles and obstructing syringoceles. All of the non-obstructing syringoceles presented with a combination of urinary tract infection (UTI), fever, and/or urinary incontinence. All of the obstructing syringoceles had obstructive voiding symptoms or ultrasonographic evidence of obstruction (9).

Hematuria, dysuria, frequency, and recurrent UTI have also been associated with both categories of manifestation $(10,11)$. In one of the largest case reviews reported on adult syringoceles, six of seven patients had open syringoceles, five of seven patients had a history of UTI, six of seven had bloody urethral discharge, and five of seven have post-void dribbling (6).

Since the symptoms of syringocele (Table-1) are non-specific, a number of possibly more serious conditions can be at play. The functional differential diagnosis upon history and physical examination is urethral web, urethral duplication, anterior urethral valve, anterior urethral diverticulum, congenital narrowing of bulbar urethra - Cobb's collar, urethral stricture, hydrocele (12), megalourethra, periurethral abscess, perianal abscess, congenital urethral folds, prolapsed posterior urethral valve, urethral tumors, urethral stones (13-19).

Table 1 - Common symptoms of syringocele.

\begin{tabular}{ll}
\hline Open Syringocele & Closed Syringocele \\
\hline Post-void dribbling & Obstructive voiding symptoms \\
Urethral discharge & Dysuria \\
Urinary tract infection & Urinary retention \\
Obstructive voiding symptoms (less common) & Perineal pain \\
Perineal pain & \\
Hematuria & \\
\hline
\end{tabular}

The four subtypes of Cowper's syringocele as described by Maizels et al. (5) are merged into two clinical categories. Here we present common symptoms described analytically and anecdotally throughout the literature of adult and pediatric syringocele. 


\section{DIAGNOSIS}

The initial evaluation of Cowper's syringocele typically involves a thorough voiding history. A high index of suspicion justifies non-invasive imaging. Ultrasonography (US) sometimes visualizes closed cystic lesions in the anatomic region of Cowper's gland (2022). US has even been used to diagnose open syringocele. In one case report, a retrograde urethrogram was positive for large outpouching and sonourethrogram confirmed the cystic outpouchings when the urethra was distended with normal saline (4). To confirm or question US results the diagnosis should proceed with antegrade and retrograde urethrography, as this step is usually diagnostic (23). In case urethrography is contraindicated or more data is needed, cystourethroscopy, urodynamic studies, computed tomography (CT) scan, or magnetic resonance imaging (MRI) may be implemented. A proctoscopy may serve to shorten the differential diagnosis. This diagnosis algorithm is illustrated in Figure-1, and Table-2 addresses the indications for syringocele in the respective interventions.

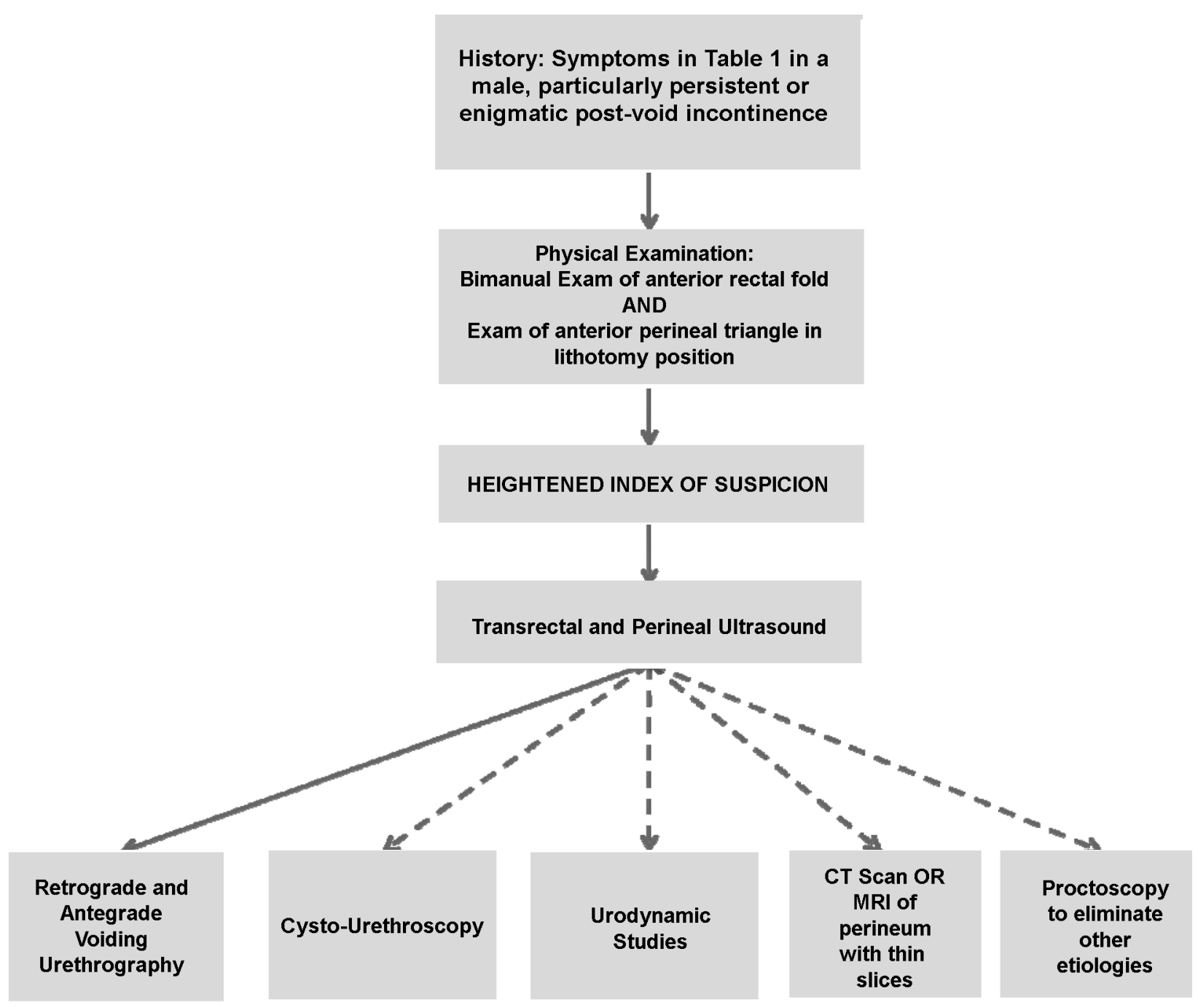

Figure 1 - Recommended diagnostic algorithm for testing. If the patient is positive for the symptoms in Table-1 after history and physical exam, syringocele can be suspected. Ultrasonography should be followed by urethrography to reliably detect syringoceles. The dashed arrows indicate the tests that are not usually necessary to diagnose syringoceles. 
Diagnosis and Management of Syringocele

Table 2 - Indications for radiologic-interventional studies to diagnose syringocele.

\begin{tabular}{|c|c|c|}
\hline Study & Open Syringocele & Closed Syringocele \\
\hline Ultrasound & $\begin{array}{l}\text { Previously absent cystic lesion } \\
\text { appreciated during retrograde } \\
\text { urethrogram }\end{array}$ & $\begin{array}{l}\text { Cystic lesions of the bulbourethral } \\
\text { glands and ducts }\end{array}$ \\
\hline $\begin{array}{l}\text { Antegrade or retrograde } \\
\text { cystourethrogram }\end{array}$ & $\begin{array}{l}\text { Cavernous filling-defect distal } \\
\text { to prostate, possible obstruction }\end{array}$ & Cystic defect distal to prostate \\
\hline Cystourethroscopy & $\begin{array}{l}\text { Defect in continuity of } \\
\text { posterior urethral wall }\end{array}$ & $\begin{array}{c}\text { Abnormal protrusion of posterior } \\
\text { urethral wall }\end{array}$ \\
\hline Magnetic resonance imaging (MRI) & Not described & $\begin{array}{l}\text { Homogenous, cystic lesion of } \\
\text { bulbourethral gland, with high-signal } \\
\text { intensity of T2-weighted scan. } \\
\text { Non-enhancement with dimeglumine } \\
\text { gadopentetate contrast. }\end{array}$ \\
\hline Computed tomography & Not described & Homogenous cystic lesion \\
\hline
\end{tabular}

There are many diagnostic modalities to diagnosis various types of syringocele, but retrograde and voiding cystourethrogram are most common in the literature. Ultrasound has found a role as a minimally invasive means to address clinical suspicion of syringocele but is not sensitive enough to rule-out pathology. The role of MRI is further being defined though its use has been limited to date.

Symptomatic, closed syringoceles often have abnormal retrograde and voiding cystourethrograms. They can present as a cystic filling defect distal to any potential prostatic obstruction. The radiologic finding can be corroborated by uroflowometry that indicates obstructive voiding rates (24). Cystourethroscopy sometimes detects an abnormal protrusion from posterior wall of the bulbous urethra, raising the index-of-suspicion for closed syringocele.

However, open syringoceles often can present with simultaneous dysuria and post-void dribbling. They too can have an obstructive pattern if the membranous flap acts in a "ball-and-chain" fashion to cause transient urethral obstruction. Cystourethrogram can be non-diagnostic but may indicate obstruction and/or cavernous filling in adjacent urethral structure. Cystourethroscopy often reveals a defect in the continuity of the posterior bulbous urethral wall, a remnant piece of cystic wall, and/or a dilated luminal orifice (25).

MRI is a non-invasive diagnostic modality continuing to define itself in diagnosis and management of Cowper's syringocele. It is found to be of particular benefit in evaluation of closed syringoceles and has been successfully applied to both the adult and pediatric population $(26,27)$. MRI has supplanted CT due to its higher soft-tissue resolution; nonetheless CT still has a diagnostic role especially when MRI is contraindicated (28).

\section{TREATMENT OF SYRINGOCELES}

Asymptomatic syringoceles are often observed (25). Although many symptomatic ones eventually require surgical intervention, a trial period of conservative management seems prudent, as spontaneous resolution of symptoms over time is not uncommon. Bevers et al. have described several cases of confirmed both open and closed syringoceles whose symptoms resolved on their own. One case resolved after successful treatment for a UTI; others resolved with no intervention (6).

In recent years endoscopic intervention has become the preferred intervention for symptomatic syringocele's. Typically unroofing the cyst by removing its visage to the urethra is a simple, effective way of marsupialization for both open and closed syringo- 
celes. In Bevers et al. case series, all four patients who went this urethroscopic intervention had complete resolution of their symptoms with a maximum follow-up interval of 23 months (mean 12 months) (6). Unroofing typically uses a cold-knife; however, the Holmium: YAG laser was successfully used in one case report (29).

Alternatively, open procedures such as transperineal ligation of the Cowper's duct are performed but are usually secondary to failed unroofing (30). Open excision may be of benefit when the syringocele presents as a large perineal mass (31). Laparoscopic excision-ligation of Cowper's gland has been described as another treatment modality and may be of benefit but no trial has born this out (32).

The pediatric population can be treated with transurethral endoscopic unroofing as well. However, current opinion recommends open intervention for certain populations, such as children with large diverticula and inadequate spongiosum. In such cases, diverticulectomy should be considered (9,33-35). In the infant population where severe reflux exists due to an anterior urethral valve phenomenon secondary to syringocele, urinary diversion and vesicostomy should be considered $(36,37)$.

\section{CONCLUSION}

Clinically it is more convenient to classify the cystic dilation of the Cowper's Gland ducts as either open or closed, in terms of communication with the urethra, than the older system proposed by Maizels et al. The symptoms of the two types of syringocele can be categorized, albeit with some overlap. Usually post-void dribbling, hematuria, or urethral discharge indicates open syringocele, while obstructive symptoms are associated with closed syringoceles. As these symptoms are shared by many serious conditions, a working differential diagnosis is critical. Once the index of suspicion is established, transrectal and perineal US followed by retrograde and antegrade urethrography can effectively diagnose syringoceles. Other diagnostic technologies, such as cystourethroscopy, urodynamic studies, CT scan, and MRI, may be used to attain supplemental data. Treatment of the lesion should first proceed conservatively under observation, as symptoms may spontaneously resolve. Persistent symptoms are the benchmark for intervention, and endoscopic marsupialization has become the standard treatment for both open and closed syringocele, but open ligation-excision may be indicated in children. Although the success rates are high for syringocele diagnosis and treatment, more comparative data is essential for establishing standard protocols.

\section{CONFLICT OF INTEREST}

None declared.

\section{REFERENCES}

1. Chughtai B, Sawas A, O'Malley RL, Naik RR, Ali Khan S, Pentyala S: A neglected gland: a review of Cowper's gland. Int J Androl. 2005; 28: 74-7.

2. Masson JC, Suhler A, Garbay B: Cowper's canals and glands. Pathological manifestations and radiologic aspects. J Urol Nephrol (Paris). 1979; 85: 497-511.

3. Sanders MA: William Cowper and his decorated copperplate initials. Anat Rec B New Anat. 2005; 282: 5-12.

4. Kumar J, Kumar A, Babu N, Gautam G, Seth A: Cowper's syringocele in an adult. Abdom Imaging. 2007; 32: 428-30.

5. Maizels M, Stephens FD, King LR, Firlit CF: Cowper's syringocele: a classification of dilatations of Cowper's gland duct based upon clinical characteristics of 8 boys. J Urol. 1983; 129: 111-4.

6. Bevers RF, Abbekerk EM, Boon TA: Cowper's syringocele: symptoms, classification and treatment of an unappreciated problem. J Urol. 2000; 163: 782-4.

7. Sant GR, Kaleli A: Cowper's syringocele causing incontinence in an adult. J Urol. 1985; 133: 279-80.

8. Shintaku I, Ono Y, Katoh N, Takeda A, Ohshima S: Anterior urethral diverticulum produced by Cowper's gland duct cyst. Int J Urol. 1996; 3: 412-3.

9. Campobasso P, Schieven E, Fernandes EC: Cowper's syringocele: an analysis of 15 consecutive cases. Arch Dis Child. 1996; 75: 71-3.

10. Awakura Y, Nonomura M, Fukuyama T: Cowper's syringocele causing voiding disturbance in an adult. Int J Urol. 2000; 7: 340-2.

11. Månsson W, Colleen S, Holmberg JT: Cystic dilatation of Cowper's gland duct--an overlooked cause of 
urethral symptoms? Scand J Urol Nephrol. 1989; 23: 3-5.

12. Marte A, Prezioso M, Sabatino MD, Borrelli M, Romano M, Del Balzo B, et al.: Syringocele in children: an unusual presentation as scrotal mass. Minerva Pediatr. 2009; 61: 123-7.

13. Vega RE: Distal urethral web: a risk factor in prostatitis. Prostate Cancer Prostatic Dis. 2002; 5: 180-2.

14. Zugor V, Schreiber M, Labanaris AP, Weissmüller J, Wullich B, Schott GE: Urethral duplication: long-term results for a rare urethral anomaly. Urologe A. 2008; 47: 1603-6.

15. Myers RP, Cahill DR, Kay PA, Camp JJ, Devine RM, King BF, et al.: Puboperineales: muscular boundaries of the male urogenital hiatus in 3D from magnetic resonance imaging. J Urol. 2000; 164: 1412-5.

16. Kajbafzadeh A: Congenital Urethral Anomalies in Boys. Part II. Urol J. 2005; 2: 125-131.

17. Mutlu N, Culha M, Mutlu B, Acar O, Turkan S, Gokalp A: Cobb's collar and syringocele with stone. Int J Clin Pract. 1998; 52: 352-3.

18. Dewan PA: A study of the relationship between syringoceles and Cobb's collar. Eur Urol. 1996; 30: 119-24.

19. Dewan PA, Keenan RJ, Morris LL, Le Quesne GW: Congenital urethral obstruction: Cobb's collar or prolapsed congenital obstructive posterior urethral membrane (COPUM). Br J Urol. 1994; 73: 91-5.

20. Strasser H, Frauscher F, Klauser A, Mitterberger M, Pinggera GM, Rehder P, et al.: Transrectal three dimensional sonography. Techniques and indications. Urologe A. 2004; 43: 1371-6.

21. Pavlica P, Barozzi L, Stasi G, Viglietta G: Ultrasonography in syringocele of the male urethra (ultrasoundurethrography). Radiol Med. 1989; 78: 348-50.

22. Yagci C, Kupeli S, Tok C, Fitoz S, Baltaci S, Gogus O: Efficacy of transrectal ultrasonography in the evaluation of hematospermia. Clin Imaging. 2004; 28 : 286-90.

23. Watson RA, Lassoff MA, Sawczuk IS, Thame C: Syringocele of Cowper's gland duct: an increasingly common rarity. J Urol. 2007; 178: 285.

24. Richter S, Shalev M, Nissenkorn I: Late appearance of Cowper's syringocele. J Urol. 1998; 160: 128-9.

25. Campobasso P, Schieven E, Sica F: Cowper's syringocele in children: report on ten cases. Minerva Pediatr. 1995; 47: 297-302.

26. Selli C, Nesi G, Pellegrini G, Bartoletti R, Travaglini F, Rizzo M: Cowper's gland duct cyst in an adult male. Radiological and clinical aspects. Scand J Urol Nephrol. 1997; 31: 313-5.
27. Kickuth R, Laufer U, Pannek J, Kirchner TH, Herbe E, Kirchner J: Cowper's syringocele: diagnosis based on MRI findings. Pediatr Radiol. 2002; 32: 56-8.

28. Merchant SA, Amonkar PP, Patil JA: Imperforate syringoceles of the bulbourethral duct: appearance on urethrography, sonography, and CT. AJR Am J Roentgenol. 1997; 169: 823-4.

29. Piedrahita YK, Palmer JS: Case report: Cowper's syringocele treated with Holmium:YAG laser. J Endourol. 2006; 20: 677-8.

30. Santin BJ, Pewitt EB: Cowper's duct ligation for treatment of dysuria associated with Cowper's syringocele treated previously with transurethral unroofing. Urology. 2009; 73: 681.e11-3.

31. Redman JF, Rountree GA: Pronounced dilatation of Cowper's gland duct manifest as a perineal mass: a recommendation for management. J Urol. 1988; 139: 87-8.

32. Cerqueira M, Xambre L, Silva V, Prisco R, Santo $\mathrm{R}$, Lages $\mathrm{R}$, et al.: Imperforate syringocele of the Cowper's glands laparoscopic treatment. Actas Urol Esp. 2004; 28: 535-8.

33. McLellan DL, Gaston MV, Diamond DA, Lebowitz RL, Mandell J, Atala A, et al.: Anterior urethral valves and diverticula in children: a result of ruptured Cowper's duct cyst? BJU Int. 2004; 94: 375-8.

34. Oesch I, Kummer M, Bettex M: Congenital urethral diverticula in boys. Eur Urol. 1983; 9: 139-41.

35. Kaneti J, Sober I, Bar-Ziv J, Barki Y: Congenital anterior urethral diverticulum. Eur Urol. 1984; 10: 48-52.

36. Rushton HG, Parrott TS, Woodard JR, Walther M: The role of vesicostomy in the management of anterior urethral valves in neonates and infants. J Urol. 1987; 138: 107-9.

37. Van Savage JG, Khoury AE, McLorie GA, Bägli DJ: An algorithm for the management of anterior urethral valves. J Urol. 1997; 158: 1030-2.

\section{Accepted after revision:} August 31, 2009

\section{Correspondence address:}

Dr. S. Ali Khan

Professor of Urology

HSC level 9, room 040

SUNY at Stony Brook

New York, 11794-8093, USA

Fax: + 1631 444-7621

E-mail: saakhan@notes.cc.sunysb.edu 


\section{EDITORIAL COMMENT}

Keep in mind the possibility of syringocele diagnosis is the greatest message by Melquist et al. in this article. The authors conducted an excellent review about this disease, unknown by many urologists. Usually identified in the pediatric population, its occurrence has been increasingly reported in adults as well. Once it shares its symptoms with a variety of other urinary tract diseases, auxiliary methods of diagnosis are required. However, the lack of comparative studies between different imaging methods does not allow a definitive conclusion about the most effective one. Despite the higher cost, MRI adds the greatest amount of information, useful not only for diagnosis but also for the therapeutic decisions to be taken. Among the invasive methods, urethroscopy is the confirmatory procedure.
Another important aspect highlighted in this review was the possibility to simplify the syringocele classification in only two types - non-obstructing syringoceles and obstructing syringoceles. Such categorization allows a better understanding of its physiopathology, as well as, suggesting the appropriate treatment.

There is limited international published literature about syringocele and this review should encourage urologists to the search for this diagnosis as a differential possibility for bladder outlet obstruction and recurrent urinary tract infections. identify it.

You need to know the disease before you can

Dr. José Carlos Truzzi Section of Urology Federal University of Sao Paulo, UNIFESP Sao Paulo, SP, Brazil E-mail:jctruzzi@hotmail.com 